\title{
A Espera na Era da Pre(s)sa 84
}

\section{Fernanda Fazzio 85}

Nesta atualidade apre(s)sada e excessiva, a todo momento temos mensagens nos celulares, vídeos que viralizam e áudios (músicas, mensagens etc.) que parecem deixar pouco espaço para a espera. Além da viralização dos conteúdos digitais fomos tomados, em meados de Março de 2020, pela pandemia de COVID-19 que mudou o nosso modo de perceber o tempo e nos relacionar com o outro. $\mathrm{O}$ isolamento social ou a quarentena como medidas profiláticas impõem que o encontro entre analista e paciente seja virtual. Contudo, o vírus digital não atinge os sujeitos como o vírus real. Esse último chega a nos lembrar de questões duras para nós: perdas, incertezas, finitude. Já a viralização da virtualidade se impõe como reação à essas ameaças de castração: elide à falta, suprime o tempo do tédio, diminui as distâncias e elimina a separação.

Em tempos de COVID-19, nossa relação com o tempo sofreu rupturas. Perdemos nossa liberdade, nossos projetos, nossas rotinas, deixando o tempo, ainda preso nas exigências da pres(s)a, com marcas de (des)continuidades. E, nessa reviravolta atual, somos presas da COVID-19 e temos pressa em superá-la. Se, já estávamos mergulhados nos excessos da temporalidade digital sem espaços vazios, atualmente, nos vemos mergulhados em um tempo tipicamente cíclico/repetitivo, em que há ruptura com as modulações temporais antes conhecidas e familiares.

A Era da Pre(s)sa, marcada pela aceleração e pelo achatamento dos intervalos temporais, ainda mostra seus imperativos mesmo em tempos em que fomos forçados a desacelerar. Os ideais de produtividade e eficiência parecem querer avançar na contramão das impossibilidades reais que o contexto de pandemia forçosamente coloca.

As considerações sobre o tempo lógico de Lacan (1998) nos ajudam a entender como abreviamos o tempo da espera da Era da Pre(s)sa. Tempo esse que é do encontro do sujeito com a dúvida, com o vazio, com as possibilidades de

\footnotetext{
84 Apresentado em Trabalhos livres no II Simpósio Bienal SBPSP "Fronteiras da Psicanálise: a clínica em movimento". no dia 21 de agosto de 2020. Derivado da dissertação de mestrado em Psicologia Clínica na PUC-SP, O tempo e o impacto da experiência estética na Era da Pre(s)sa: psicanálise e teatro performático (2010), com apoio da CNPQ, e orientação do Prof. Dr. Renato Mezan.

85 Mestre em Psicologia Clínica (PUC-SP), especialista em Semiótica Psicanalítica (PUC-SP) e membro efetivo do Departamento de Psicanálise com Crianças do Instituto Sedes Sapientiae.
} 
aguçar sua sensibilidade e criatividade, transformando, assim, sensações em experiências. A temporalidade, para o psicanalista Jacques Lacan, atravessa três momentos fundamentais: o instante de olhar (constatação do que se pode ver), o tempo de compreender (tempo de elaboração de uma hipótese, de raciocínio, de mediação que considera o outro) e o momento de concluir (tempo de agir, que pede certa urgência). Diante da velocidade imposta na Era da Pre(s)sa, os sujeitos podem passar, aceleradamente, do instante de olhar para o momento de concluir. Como efeito, o tempo de compreender ficaria então como um hiato, em suspensão, atropelado por esse tempo exigente de respostas.

Através das câmeras dos celulares, vamos até a casa de nossos pacientes, e eles na nossa. Enquanto alguns pacientes relatam maior intimidade no atendimento online e ampliações perceptivas ao falarmos "em seu ouvido", outros mostram uma sensação de distanciamento, como se o olhar do analista precisasse encontrar com o seu.

A horizontalidade ganha grifos nas análises online. Basta vermos como quão rapidamente as crianças nos levam para "passear" nas casas, expandindo o setting analítico. Outras vezes, já aprendem a sair do enquadre de visão, colocar imagens nas telas e inverter a câmera, por exemplo, para que não as vejamos. Essas mudanças no enquadre podem ser incluídas na escuta do analista e interpretadas. Será que as crianças querem controlar o setting ou expressar a raiva? Em outros momento, essa presença e ausência podem também virar uma brincadeira de esconde-esconde. Rapidamente, as regras do setting se alteram adquirem outros limites e possibilidades.

Nos consultórios virtuais, são muitos os pacientes que falam de suas relações pessoais mediadas pelas redes sociais. Os sujeitos exaltam seu lado mais espetacular, feliz, perfeito e invejável nas redes sociais, o que leva seu Eu-ideal a encontrar a máxima representação na vida das janelas virtuais. Se essa vida espetacular não se equipara à vida por trás das câmeras sem seus tantos filtros, os sujeitos, através dos espelhos (virtuais), acreditam poder viver uma vida bidimensional. E, em tempos de pandemia, com terapia virtuais, como escapar da espetacularização também da relação analista e paciente que acontece por intermédio das telas? E, assim, esse truque também pode recair para os analistas: atrás das telas mágicas que se iluminam para algo acontecer, os pacientes podem se ver tentados a entrar na lógica espetacular, perdendo a dimensão da 
experiência e do encontro. Não por acaso, em alguns atendimentos, foi comum que os pacientes se comportassem como youtubers. Ao invés de estarem na relação analítica de fato, queriam mostrar como fazer coisas, imitando os modos de falar e os gestos dos youtubers.

A análise se baseia no encontro entre analista e paciente numa construção gradativa e minuciosa em que olhar e voz se enlaçam nas pulsões. Nesse sentido, a análise tem o seu próprio tempo e há um desafio em estabelecer esse compasso no dinamismo com o qual, inevitavelmente, nos deparamos nos atendimentos online. O próprio tempo digital tem lá as suas interferências: conexão fraca, queda do wi-fi, voz metálica e com atraso, congelamento da tela, e por aí vai. Impossível manter contato olho-no-olho, dado o natural desencaixe do dispositivo de câmera do computador/celular com os olhos do seu interlocutor. Portanto, os olhares não se cruzam, sendo impossível olhar, simultaneamente, para a câmera e para a expressão do outro. Além disso, a voz digital não é a mesma voz encarnada, sofrendo pequenas alterações, limitando as intervenções do analista, bem como as interpretações, que podem chegar atrasadas ou em um tempo outro, perdendo o momento do encontro.

Em tempos de COVID-19, privacidade se torna, por vezes, impossível, esgarçando as relações daqueles que passam juntos o confinamento. Acompanhamos adultos e crianças marcados pelos excesso de presença, sufocando os vínculos familiares. Não podemos nos esquecer das aulas online e vídeo-aulas que também implicam na presença dos pais para ajudar as crianças nas aulas e tarefas, dificultando ainda mais a privacidade das crianças. Nesse contexto, se diluíram um pouco as fronteiras entre o tempo "fora" e "dentro", trazendo a presença do outro de modo excessivo.

No momento atual, nós analistas e também os familiares, buscamos dar suporte para a continuidade de ser, visando recuperar a dimensão da continuidade do tempo, tecer memórias e construir uma história que possa ser contada. Acompanho algumas famílias que tem escrito "diários da quarentena" na tentativa de manter a memória desse momento. Escutei relatos de um pai que estava montando um álbum de fotos das coisas que ele e os filhos estão fazendo juntos na quarentena: bolos e pães com receitas dos avós, cuidar do aquário, montar quebra-cabeças e a jogar novos jogos de tabuleiro. Esse mesmo pai também comenta sobre as dificuldades em separar as fronteiras dos espaços de 
"trabalho" e de "brincadeira", como se estar em casa fosse entendido pelos filhos como sinônimo de disponibilidade.

Os efeitos do brilho da tela ficam ainda mais contundentes quando as crianças atingem a primeira infância. $\mathrm{O}$ sofrimento das crianças dão notícias sobre o mal-estar da cultura em sua forma mais espontânea. A psicanalista Jerusalinsky (2017) nos ajuda a entender que, no contexto de excessos de informações e estímulos, os conteúdos tóxicos chegam de forma violenta, sobretudo para as crianças pequenas, que têm menos recursos para digerir o que foi percebido. A violência simbólica pode ter várias faces, e uma delas pode se dar pelos excessos que chegam via tecnologia.

Dito isso, o desafio da análise psicanalítica é enlaçar o impossível de ser dito, possibilitando a inscrição de um real demasiadamente excessivo, que insiste em não se deixar inscrever. Diante da dificuldade das crianças em representar a invisibilidade do vírus, vemos como os pesadelos e as regressões (enureses) tem se intensificado, bem como os temas de monstros, zumbis e super-heróis tem tido maior presença, talvez, como tentativa das crianças de encontrar formas para esse mortífero que se encontra à espreita. Assim, no momento atual, nós analistas e também os familiares, buscamos dar suporte para a continuidade de ser, visando recuperar a dimensão da continuidade do tempo, tecer memórias e construir uma história que possa ser contada.

O encontro analítico, em meios digitais, se depara com desafios para trazer o caráter pulsional do encontro bidimensional, chapado e passivo que as telas propõem. Não podemos falar que não há um corpo no virtual. Mesmo que seja de outra ordem, existe uma materialidade do corpo, que, nesse caso, fica em outro registro perceptivo, em outro lugar. Ademais, sobretudo em atendimentos a crianças muito pequenas, são inegáveis os efeitos presenciais da voz e do olhar para que o encontro aconteça, implicando em ainda mais desafios para os atendimentos online. Nesses momentos, vemos como o papel dos pais é importante para preservar a intimidade do espaço analítico e também, quando necessário, sua presença para ajudar e permitir que o encontro ocorra.

A tela convida à espetacularização, como os youtubers que encantam as crianças, enquanto se instaura uma relação passiva entre aquele que mostra e o outro que assiste. Em sentido contrário, uma análise caminha em direção ao inesperado que possa surgir do encontro, sempre imprevisível, com o outro. Não 
por acaso, as parlendas, a polifonia da linguagem, as modulações da voz, os malentendidos, os equívocos, o humor e toda a espontaneidade do brincar implicam na abertura de inúmeras possibilidades de criação. $\mathrm{E}$, ainda que tenham entraves e empecilhos nos atendimentos online, é preciso buscarmos chegar até o outro do outro lado da tela, sejam crianças, adolescentes ou adultos.

Em tempos atuais, as demandas por análise não cessam. Ultrapassando a concretude do consultório, buscamos alcançar o outro que sofre. Tentamos, assim, transpor o corpo erógeno, simbólico e pulsional para além dos limites da bidimensionalidade, validando que é possível que o olhar e a voz toquem efetivamente o outro. Nós, analistas, assim, estamos nos adaptando às formas e aos ritmos das imagens propostas em uma sessão virtual. Nesse contexto, não se trata de uma simples passagem das sessões presenciais para as sessões online, mas, diferentemente, me parece muito relevante procurarmos refletir sobre as novas configurações e as formas de presença, e escutar o que os pacientes nos dizem através dos usos da tecnologia. Daí a importância de nos flexibilizarmos às circunstâncias, assim como às necessidades e às demandas dos pacientes.

\section{Referências}

Baptista A, Jerusalinsky $J$ (orgs). Intoxicações eletrônica: o sujeito na era das relações digitais. Salvador: Álgama; 2017.

Debord G. A sociedade do espetáculo: comentários sobre a sociedade do espetáculo. Rio de janeiro: Contraponto; 1997.

Freud S (1917). Luto e melancolia. Textos: Maria Rita Kehl, Modesto Carone e Urania Tourino Peres. São Paulo: Cosac Naify; 2011

Freud S (1930-1936). O mal-estar na civilização, novas conferências introdutórias à psicanálise e outros textos. São Paulo: Companhia das Letras; 2010.

Freud S (1905). "Três ensaios sobre a teoria da sexualidade". Obras psicológicas completas de Sigmund Freud vol VII. Rio de Janeiro: Imago; 1996.

Freud S. (1919). "O Estranho". In: Freud S. Obras Completas de Sigmund Freud - Vol. XVII. Rio de Janeiro: Imago; 1996.

Freud S. (1914). "Sobre o Narcisismo: uma introdução". In: Freud S. Obras Completas de Sigmund Freud - Vol. XVII. Rio de Janeiro: Imago; 1996. 
Kehl MR. O tempo e o cão: a atualidade das depressões. São Paulo: Boitempo; 2009.

Lacan J. "O estádio do espelho como formador da função do eu”. Escritos Rio de Janeiro: Jorge Zahar; 1998

Lacan, J. O tempo lógico e a asserção de certeza antecipada. In: J. Lacan. Escritos. Rio de Janeiro: Jorge Zahar; 1998

Jerusalinsky J. Que rede nos sustenta no balanço da vida? O sujeito na era das relações virtuais. In: Baptista A, Jerusalinsky J (orgs). Intoxicações eletrônica: o sujeito na era das relações digitais. Salvador: Álgama; 2017. 